\title{
Design of a Network with Sensor-Cloud Technology Applied to Traffic Accident Prevention
}

\author{
Autores \\ Amelec Viloria, Noel Varela, Yaneth Herazo-Beltran, Omar Bonerge Pineda Lezama
}

\begin{abstract}
The main goal of this research is to facilitate the connection of sensors, people and objects to build a centralized community with parameter measurement applications, where people can share and analyze sensor data in real-time. For example, public institutions that plan, regulate and control land transport, traffic and road safety, and that aim to increase the level of road safety, would be able to prevent traffic accidents by monitoring public transport vehicles in realtime. To obtain real-time data, transport units would be installed with biosensors and a video camera, which would send a series of data automatically for storage and processing in the sensor cloud. The data will allow the recognition of facial expressions and the analysis of physiological variables to determine the driver's mood, according to which immediate actions will be taken to control this variable; and through an audible alarm or a led screen, the actions to be taken by the driver or the passenger would be explained, and even an automatic setting of the interior of the vehicle can be carried out and the emergency units informed according to the case.
\end{abstract}

Palabras clave

WSN, Cloud computing, 6LowPAN, Sensor cloud 